See discussions, stats, and author profiles for this publication at: https://www.researchgate.net/publication/330894042

\title{
Multiple zero group velocity Lamb modes in an anisotropic plate: propagation along different crystallographic axes
}

Article in Canadian Journal of Physics · February 2019

DOl: 10.1139/cip-2018-0348

\section{CITATIONS}

5 authors, including:

Soufiane Karous

KU Leuven

1 PUBLICATION 0 CITATIONS

SEE PROFILE

M. S. Bouhdima

Institut Supérieur des Sciences Appliquées et de Technologie de Gabès 6 PUBLICATIONS 7 CITATIONS

SEE PROFILE
154

Souhail Dahmen

7 PUBLICATIONS 78 CITATIONS

SEE PROFILE

Ben Amor Morched

Institut Préparatoire aux Etudes d'Ingénieurs de Sfax

26 PUBLICATIONS 130 CITATIONS

SEE PROFILE

Some of the authors of this publication are also working on these related projects:

wave propagation in PM/PE layers View project

Analysis of the vibration behavior of a functionally graded piezoelectric plate at ZGV resonance frequency View project 
1 Multiple zero group velocity Lamb modes in an anisotropic plate: propagation along

2

3

4

5

6

\section{different crystallographic axes.}

Soufien Karous ${ }^{(\mathrm{a})^{*}}$, Souhail Dahmen ${ }^{(\mathrm{a})}$, Mohamed Shili Bouhdima ${ }^{(\mathrm{a})}$,Morched Ben Amor ${ }^{(\mathrm{a})}$, and Christ Glorieux $^{(\mathrm{b})}$

${ }^{a}$ Laboratory of Physics of Materials, Faculty of Science of Sfax, BP 1171, 3000 University of Sfax, Tunisia.

${ }^{\mathrm{b}}$ Laboratory of Acoustics, Division of Soft Matter and Biophysics, Department of Physics and Astronomy, KU Leuven, Celestijnenlaan 200D, B3001 Heverlee, Belgium.

* Corresponding author:

E-mail address: soufien.karous1a@gmail.com

\section{Abstract:}

The paper studies the propagation of symmetric and anti-symmetric Lamb waves along iodic acid plate $\left(\mathrm{HIO}_{3}\right), 1 \mathrm{~mm}$ thick, in the 1 to $50 \mathrm{MHz}$ frequency range. The Lamb modes propagation along three crystallographic planes was theoretically investigated, for two mutually orthogonal propagation directions. Several frequencies were found which correspond to Lamb modes with zero group velocity (ZGV) and non-null phase velocity values. The first symmetric Lamb mode, $\mathrm{S}_{1}$, was found to possess only one $\mathrm{ZGV}$ point, regardless of the propagation direction; higher order symmetric and anti-symmetric modes with up to four ZGV points were found, depending on the propagation plane. The dependence of the ZGV frequencies on each elastic constant $\left(\mathrm{c}_{11}, \mathrm{c}_{13}, \mathrm{c}_{33}, \mathrm{c}_{55}\right)$ of the $\mathrm{HIO}_{3}$ plate material was also investigated by changing the constant values by $5 \%$ and $10 \%$. It was found that $c_{33}$ and $c_{55}$ affect the number of the $\mathrm{ZGV}$ points, while $\mathrm{c}_{11}$ and $\mathrm{c}_{13}$ affect the frequency of the $\mathrm{ZGV}$ points. The existence and frequencies of the ZGV points are strongly dependent on the proximity of standing longitudinal and transverse waves at nearby cutoff frequencies. 
Keywords: Lamb waves, anisotropic plate, $\mathrm{HIO}_{3}$, multiple zero-group velocity points, elastic properties.

\section{INTRODUCTION}

One of the important ultrasonic approaches for nondestructive evaluation in industry makes use of the dependence of the experimentally accessible dispersive behavior of the velocity of Lamb waves on the elastic properties of the plates in which they are propagating, making their behavior a widely addressed topic of investigation [1-4]. The possibility to measure the dispersion characteristics of Lamb modes has also often been exploited to extract the mechanical properties of materials [5-9]. Recently, the existence of extrema in the phase velocity dispersive curve, which correspond to Lamb waves with zero group velocity, has attracted quite some attention [10-12]. When a range of frequencies in the neighborhood of such a zero group velocity ( $\mathrm{ZGV}$ ) point are excited, then a standing wave pattern induced by the interference of forward and backward waves can be observed, for which there is no net outflow of energy from the excitation region, resulting in a locally very strong resonance phenomenon [13-16]. The typically very high Q-factor of this resonance yields a quite accurate way to extract the local mechanical properties of the plate from the resonance frequency [17-22]. This feature has been exploited for local and non-contact measurement of mechanical properties of plates $[23,24]$ and for in-service nondestructive evaluations [ 25].

An incentive to researchers to study the behavior of ZGV points to characterize anisotropic plates comes from the increased use of fiber reinforced materials for automotive and aviation applications where the damages evaluation is a crucial case study and the need to characterize them has been steadily growing in the recent years [19]. 
The existence of a $\mathrm{ZGV}$ resonance in the $\mathrm{S}_{1}$ mode for some materials was first pointed out by Tolstoy and Usdin in 1957 [26]. Negishi experimentally observed the negative group velocity of the $\mathrm{S}_{2}$ mode travelling along an aluminum plate, $1 \mathrm{~mm}$ thick, in 1978: he also predicted the existence of the negative group velocity of the $S_{4}$ mode [27]. Many papers on the behavior of Lamb waves in various isotropic materials have been published [14,15, 28-33]. Parygin et al. [34] found that there are modes with multiple ZGV points in an anisotropic paratellurite crystal plate. Prada et al. [19] found ZGV resonances in the $S_{1}$ and $A_{2}$ Lamb modes in a silicon plate with cubic symmetry. Hussain and Ahmad [10] revealed the existence of a multitude of ZGV points in the dispersion curves of Lamb waves propagating along one of the crystallographic axes in the $\mathrm{P}_{13}$-plane of an orthotropic $\mathrm{HIO}_{3}$ plate [10]. In reference [35] Hanyin Cui et al. have studied the influence of the outer-to-inner radius ratio in hollow cylinders in the group velocity of a backward mode to be used in acoustic logging tools. Hanyin Cui et al. [36] investigated the influences of a fluid-loading on ZGV resonances in pipes for the possible application of integrity inspections of oil transportation pipelines.

In this paper, we extend the work of Hussain and Ahmad [10], by investigating the ZGV points in an orthotropic $\mathrm{HIO}_{3}$ plate for two mutually orthogonal propagation directions in three different crystallographic planes. The influence of the elastic constants on the number of the $\mathrm{ZGV}$ points and on their frequencies is also investigated.

\section{THEORETICAL STUDY}

\section{A. The Wave propagation theory}

The theory of wave propagation in orthotropic materials has been elaborated in a number of research works [37-45]. The theory starts from the Hooke's law,

$$
T_{i j}=c_{i j k l} \cdot S_{k l}
$$


75 where $S_{k l}=\frac{1}{2}\left(\frac{\partial u_{k}}{\partial u_{l}}+\frac{\partial u_{l}}{\partial u_{k}}\right), \rho$ is the mass density of the plate material, and $\mathrm{u}_{\mathrm{i}}$ is the wave

that defines the linear relationship between stress $T_{i j}$ and strain $S_{k l}$ through the elastic constants $c_{i j k l}$, and the wave propagation equation

$$
\rho \frac{\partial^{2} u_{i}}{\partial^{2} t}=\frac{\partial T_{i j}}{\partial x_{j}}
$$

displacement component along the i direction $(i=1,2,3)$. By combining equations 1 and 2 , and solving for a plane wave solution

$$
u_{i}=u_{i}^{0} \cdot \operatorname{expj}\left(\omega t-k x_{1}\right)
$$

where $\mathrm{x}_{1}$ is the propagation direction of the wave, $\omega[\mathrm{rad} / \mathrm{s}]$ is the angular frequency, and $u_{i}^{o}$ is the wave amplitude, we obtain the three Christoffel equations [46]

$$
\sum_{l=1}^{3}\left|\Gamma_{i l}-\varrho V^{2} \delta_{i l}\right| \cdot P_{l}=0
$$

where $\delta_{\mathrm{il}}$ is Kronecker's symbol, $\mathbf{V}=\boldsymbol{\omega} / \mathbf{k}$ is the phase velocity of the wave, $\mathbf{P}$ is the polarization vector whose components are the eigenvectors corresponding to each eigenvalue (i.e. the three phase velocities) and $\Gamma_{\mathrm{i} 1}$ are the components of the $3 \times 3$ symmetric matrix:

$$
\Gamma_{i l}=\sum_{j=1}^{3} \sum_{k=1}^{3} c_{i j k l} \tilde{n}_{j} \tilde{n}_{k}
$$

where $\tilde{\mathbf{n}}$ is the unit vector in the slowness direction. The system of three equations in three unknowns (4) admits non trivial solution if the determinant of the matrix of the coefficients is equal to zero, $\operatorname{det}\left(\Gamma_{i l}-\varrho V^{2} \delta_{i l}\right)=0$ : equation (4) describes a standard eigenvalue $\left(\rho V^{2}\right)$ problem with eigenvectors $(\mathrm{P})$ for the matrix $\Gamma$. The final solutions consist in three velocities $\mathrm{V}$ $[\mathrm{m} / \mathrm{s}]$, expressed in terms of $\mathrm{c}_{\mathrm{ijkl}}$ and $\rho$, corresponding to the longitudinal, shear horizontal and shear vertical bulk waves velocities and polarization vectors. The equations system (4) can be solved for whatever propagation direction $\mathbf{n}$ with $\mathbf{n}=\tilde{\mathbf{n}}$, resulting in three positive values for $\mathrm{V}$. 
In the symmetry planes of orthotropic media, the determinant of Christoffel equations can be decomposed into linear and quadratic factors for $\mathrm{V}^{2}$. The roots of the quadratic factor correspond to quasi longitudinal and quasi-transverse bulk wave velocities: the polarization of the modes has no shear horizontal component.

\section{B. Dispersion curves of Lamb waves in a plate}

Lamb modes travel along finite thickness plates, hence the boundary conditions must be added to the problem of the waves propagation in unbonded media, i.e. by assuming that the top and bottom surfaces of the plate are traction-free surfaces,

$$
T_{i 3}=0, \quad \text { at } x_{3}=0 \text { and } x_{3}=h
$$

according to fig.1. We assume that Lamb waves propagate in the $\mathrm{x}_{1}$-direction in an orthotropic plate of thickness $\mathrm{h}$ with the sagittal plane lying in the (010) crystallographic plane denoted as $\mathrm{P}_{13}$, as shown in Fig.1. The Lamb modes propagation was also investigated along the $\mathrm{x}_{1} \mathrm{x}_{2}$ and $\mathrm{x}_{2} \mathrm{x}_{3}$ sagittal planes, for two mutually orthogonal propagation directions. We adopted the following convention to identify the crystallographic plane under study, $\mathrm{P}_{\mathrm{ij}}$ : the index i refers to the propagation direction and the index $\mathrm{j}$ represents the axis aligned to the plate depth.

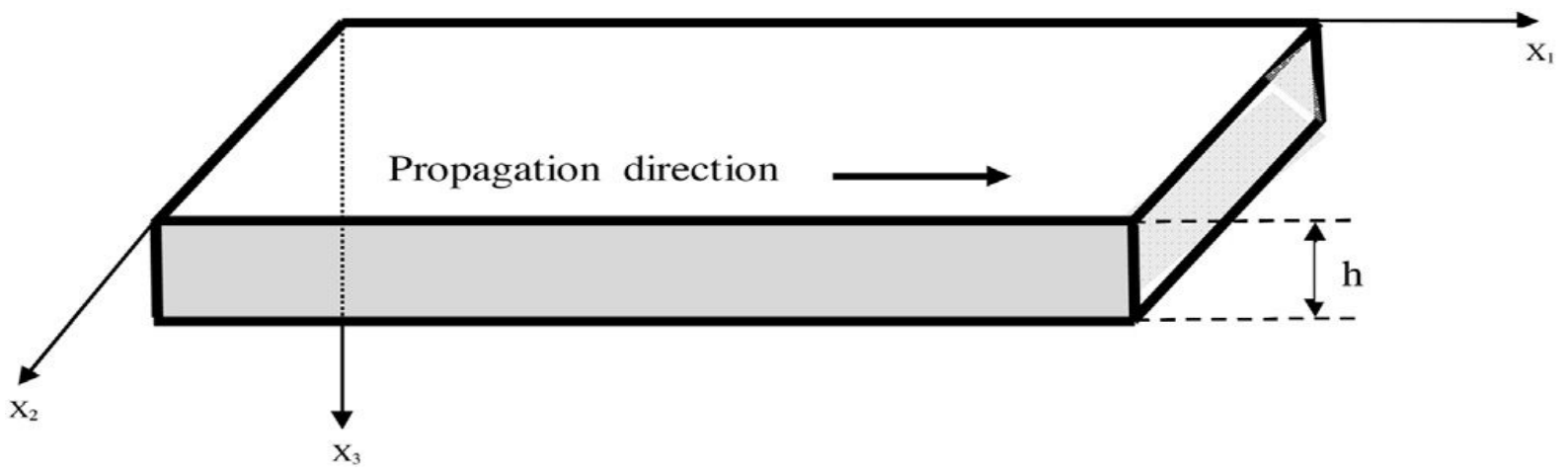

FIG.1. The geometry of the homogeneous plate, showing the coordinate system. 
112 In this case the Lamb waves travelling along the $\mathrm{HIO}_{3}$ plate are decoupled from the shear horizontal $(\mathrm{SH})$ wave [43] $\left(\mathrm{n}_{2}=0\right)$ and the elements of the equation $(5)$ are reduced to:

$$
\Gamma_{i k}=c_{i 1 k 1} \cdot n_{1}^{2}+\left(c_{i 1 k 3}+c_{i 3 k 1}\right) \cdot n_{1} \cdot n_{3}+c_{i 3 k 3} \cdot n_{3}^{2}
$$

Performing a root search of $\operatorname{det}(\Gamma)=0$, then the components of the polarization vector along the $\mathrm{x}_{1}$ and $\mathrm{x}_{3}$ directions can be solved. The most general method for solving the propagation of Lamb waves is by the partial wave technique where the principle of superposition of two upward and two downward travelling plane waves are assumed while satisfying the boundary conditions. At the two stress-free plate surfaces, $x_{3}=0$ and $x_{3}=h$, the reflection of waves results in the combination of the motion of upward and downward moving quasi-longitudinal QL and quasi-shear QT waves. The top and bottom surface boundaries reflect the waves and the combination of these reflections going towards the upper or lower interfaces results in the propagating guided waves along the plate. The combination of all four waves defines a single guided wave mode. The total particle displacement vector $\mathbf{u}$ of Lamb waves can thus be expressed as a linear combination of 4 of such partial waves:

$$
\vec{u}=\sum_{j=1}^{4} A^{(j)} \vec{u}^{(j)}
$$

where $\vec{u}^{(j)}=\exp i \omega\left(\vec{n}^{(j)} \vec{x}-t\right) \stackrel{(j)}{P} \vec{P}^{(j)}$ are the displacement vectors of the 4 partial heterogeneous plane waves with polarization vectors $\mathrm{P}^{\mathrm{m}}=\left(\mathrm{P}_{1}{ }^{\mathrm{m}}, \mathrm{P}_{3}{ }^{\mathrm{m}}\right), \mathbf{n}=\left(\mathrm{n}_{1}, \mathrm{n}_{3}\right)$ is the slowness vector, $\mathbf{x}=\left(\mathrm{x}_{1}, \mathrm{x}_{3}\right)$ is the spatial coordinate vector; the index $(\mathrm{j})$ denotes the partial wave $(j=1,2$, 3, or 4 for modes $\mathrm{QL}^{\text {down }}, \mathrm{QL}^{\text {up }}, \mathrm{QT}^{\text {down }}{ }^{\mathrm{Or}} \mathrm{QT}{ }^{\mathrm{up}}$, respectively). $\mathrm{A}^{(\mathrm{j})}$, the coefficients of the partial waves constituting the Lamb wave, are to be determined by satisfying the boundary conditions equation (6) at the plate interfaces. In the absence of a source, setting the stresses equal to zero yields a homogeneous set of 4 equations in the 4 unknowns $\mathrm{A}^{(\mathrm{j})}$, inferring that in order to have non-trivial solutions, the determinant of the matrix should be zero. The latter condition can be 


$$
\frac{\operatorname{tg}\left(\omega^{Q T v} n_{3}(h)\right)}{\operatorname{tg}\left(\omega^{Q L} n_{3}(h)\right)}-\frac{\left(c_{13} n_{1}{ }^{(1)} P_{1}+c_{33}{ }^{(1)} n_{3}{ }^{(1)} P_{3}\right) \times i \omega c_{55}\left({ }^{(2)} n_{3}{ }^{(2)} P_{1}+n_{1}{ }^{(2)} P_{3}\right)}{\left(c_{13} n_{1}{ }^{(2)} P_{1}+c_{33}{ }^{(2)} n_{3}{ }^{(2)} P_{3}\right) \times i \omega c_{55}\left({ }^{(1)} n_{3}{ }^{(1)} P_{1}+n_{1}{ }^{(1)} P_{3}\right)}=0
$$

used to find the values of the Lamb wave phase velocity $v_{\mathrm{ph}}$ that are roots of the determinant. After finding the $\mathrm{v}_{\mathrm{ph}}$-values by means of a root search, for each solution $\mathrm{v}_{\mathrm{ph}}$, the corresponding partial wave coefficients $\mathrm{A}^{(\mathrm{m})}$ can be determined by arbitrarily choosing one of the 4 coefficients, and thus reducing the $4 \times 4$ set of equations to a set of 3 linearly independent equations in 2 coefficients, which can be solved, yielding an expression of each of those 3 coefficients as a function of the chosen one.

This procedure thus allows to determine, for each $\omega$ value, the possible phase velocities, the corresponding coefficients, and the corresponding displacement vectors $\mathbf{u}$.

Given the symmetry of the problem, the determinant $\mathrm{M}$ of the coefficients of the boundary conditions equations system can be rewritten as the product of 2 determinants, one for the symmetric and one for the antisymmetric Lamb modes (i.e. with displacements symmetric and antisymmetric with respect to the midplane of the plate), $M=M_{s} \cdot M_{a}$, resulting in separate determinant equations $\operatorname{det}\left(\mathrm{M}_{\mathrm{s}}\right)=0$ and $\operatorname{det}\left(\mathrm{M}_{\mathrm{a}}\right)=0$. These equations can be solved analytically, yielding the following implicit dispersion relations for symmetric modes

$$
\frac{\operatorname{tg}\left(\omega^{Q T v} n_{3}(h)\right)}{\operatorname{tg}\left(\omega^{Q L} n_{3}(h)\right)}-\frac{\left(c_{13} n_{1}{ }^{(2)} P_{1}+c_{33}{ }^{(2)} n_{3}{ }^{(2)} P_{3}\right) \times i \omega c_{55}\left({ }^{(1)} n_{3}{ }^{(1)} P_{1}+n_{1}{ }^{(1)} P_{3}\right)}{\left(c_{13} n_{1}{ }^{(1)} P_{1}+c_{33}{ }^{(1)} n_{3}{ }^{(1)} P_{3}\right) \times i \omega c_{55}\left({ }^{(2)} n_{3}{ }^{(2)} P_{1}+n_{1}{ }^{(2)} P_{3}\right)}=0
$$

and for antisymmetric modes, as function of the unknown $\mathrm{v}_{\mathrm{ph}}[47,48]$ :

\section{These equations remain valid for any material of higher symmetry class, assuming that the} direction of propagation is collinear with a principal axis [41]. Solutions to these equations are coupled $\omega$ and $v_{p h}$ values: they are obtained using a numerical process based on the dichotomy method to find initial solutions at specific angular frequencies, plus the Newton-Raphson method used to follow these roots as the angular frequency changes [45, 49]. 
157

158

159

160

161

162

163

164

165

166

167

168

169

170

171

$172 f_{c} \cdot h=(m+1) / 2 \cdot V_{L}$, for mode $\mathrm{S}_{2 \mathrm{~m}+1}(\mathrm{~m} \geq 0)$

173 and for antisymmetric modes:

$174 f_{c} \cdot h=n \cdot V_{L}$, for mode $\mathrm{A}_{2 \mathrm{n}}(\mathrm{n} \geq 1)$

175

$f_{c} \cdot h=(m+1) / 2 \cdot V_{T}$, for $\operatorname{mode}_{2 \mathrm{~m}+1}(\mathrm{~m} \geq 0)$

176 where $\mathrm{n}=1,2,3, \ldots$, and $\mathrm{m}=0,1,2, \ldots$ 
177 It is noteworthy that, although the dispersion curves reported by Hussain and Ahmad [10] for 178 the same plane $\left(\mathrm{P}_{13}\right.$ plane $)$ are coinciding with the ones we have calculated, however, their 179 choice of indexing, based on sorting of modes according to their order of appearance versus 180 frequency, is not consistent with the indexing rule we have adopted which is based on the 181 number of nodes present throughout the plate cross-section $[15,49]$. E.g. the symmetric mode 182 with cutoff frequency equal to $1.673 \mathrm{MHz}$, which is denoted by Hussain and Ahmad as $\mathrm{S}_{13}$, $183[10]$ corresponds to the mode denoted as $\mathrm{S}_{11}$ in literature $[15,42,50]$ and in this work.

184 In Tables II and III we summarize respectively the symmetric and antisymmetric modes up to 185 the $42^{\text {th }}$ order, according to the number of ZGV points these modes exhibit for propagation 186 along the $\mathrm{x}_{1}$-axis in the $\mathrm{P}_{13}$ crystallographic plane in an iodic acid plate.

\begin{tabular}{|l|l|l|l|}
\hline $\begin{array}{l}\text { Modes with no } \\
\text { ZGV point }\end{array}$ & $\begin{array}{l}\text { Modes with one ZGV } \\
\text { point }\end{array}$ & $\begin{array}{l}\text { Modes with two ZGV } \\
\text { points }\end{array}$ & $\begin{array}{l}\text { Modes with } \\
\text { three ZGV } \\
\text { points }\end{array}$ \\
\hline $\mathbf{S}_{\mathbf{0}}, \mathbf{S}_{2}, \mathbf{S}_{3}, \mathbf{S}_{5}, \mathbf{S}_{\mathbf{9}}$ & $\mathbf{S}_{1}, \mathbf{S}_{4}, \mathbf{S}_{6}, \mathbf{S}_{\mathbf{7}}, \mathbf{S}_{\mathbf{8}}, \mathbf{S}_{12}$ & $\mathbf{S}_{11}, \mathbf{S}_{15}, \mathbf{S}_{17}, \mathbf{S}_{19}, \mathbf{S}_{21}$ & $\mathbf{S}_{39}, \mathbf{S}_{40}, \mathbf{S}_{46}$ \\
$\mathbf{S}_{10}, \mathbf{S}_{13}, \mathbf{S}_{16}$ & $\mathbf{S}_{14}, \mathbf{S}_{18}, \mathbf{S}_{20}, \mathbf{S}_{22}, \mathbf{S}_{24}$ & $\mathbf{S}_{23}, \mathbf{S}_{25}, \mathbf{S}_{27}, \mathbf{S}_{28}, \mathbf{S}_{29}$ & \\
& $\mathbf{S}_{26}, \mathbf{S}_{32}, \mathbf{S}_{34}, \mathbf{S}_{44}$ & $\mathbf{S}_{30}, \mathbf{S}_{31}, \mathbf{S}_{36}, \mathbf{S}_{38}, \mathbf{S}_{42}$ & \\
& & & \\
\hline
\end{tabular}

TABLE II :Classification of symmetric Lamb modes propagating along the $x_{1}$-direction in 190 the $P_{13}$ plane, according to the number of ZGV points. 


\begin{tabular}{|l|l|l|l|}
\hline $\begin{array}{l}\text { Modes with no } \\
\text { ZGV point }\end{array}$ & $\begin{array}{l}\text { Modes with one ZGV } \\
\text { point }\end{array}$ & $\begin{array}{l}\text { Modes with two ZGV } \\
\text { points }\end{array}$ & $\begin{array}{l}\text { Modes with } \\
\text { three ZGV } \\
\text { points }\end{array}$ \\
\hline $\mathbf{A}_{\mathbf{0}}, \mathbf{A}_{1}, \mathbf{A}_{3}, \mathbf{A}_{4}$ & $\mathbf{A}_{2}, \mathbf{A}_{\mathbf{5}}, \mathbf{A}_{11}, \mathbf{A}_{13}, \mathbf{A}_{15}$ & $\mathbf{A}_{6}, \mathbf{A}_{10}, \mathbf{A}_{14}, \mathbf{A}_{18}$, & $\mathbf{A}_{35}, \mathbf{A}_{41}$ \\
$\mathbf{A}_{\mathbf{8}}, \mathbf{A}_{\mathbf{9}}, \mathbf{A}_{\mathbf{1 2}}, \mathbf{A}_{29}$ & $\mathbf{A}_{16}, \mathbf{A}_{17}, \mathbf{A}_{19}, \mathbf{A}_{21}, \mathbf{A}_{23}$ & $\mathbf{A}_{20}, \mathbf{A}_{22}, \mathbf{A}_{24}, \mathbf{A}_{26}$, \\
$\mathbf{A}_{25}, \mathbf{A}_{27}, \mathbf{A}_{31}, \mathbf{A}_{33}, \mathbf{A}_{37}$ & $\mathbf{A}_{28}, \mathbf{A}_{30}, \mathbf{A}_{25}, \mathbf{A}_{27}$, \\
$\mathbf{A}_{39}$ & $\begin{array}{l}\mathbf{A}_{31} \\
\mathbf{A}_{33}, \mathbf{A}_{32}, \mathbf{A}_{34}, \mathbf{A}_{36}\end{array}$ & \\
$\mathbf{A}_{38}, \mathbf{A}_{40}$ & \\
\hline
\end{tabular}

Table III : Classification of antisymmetric Lamb modes propagating along the $x_{1}$-direction in the $P_{13}$ plane, according to the number of ZGV points.

In the following paragraphs of this paper, we take a closer look at the existence and features of ZGV points, for symmetric and antisymmetric Lamb waves propagating in $\mathrm{HIO}_{3}$ plates for differ crystallographic planes. For some cases, a study is performed to get a deeper insight on the influence of the elastic parameters on the features of the ZGV points, i.e. there existance and their frequency. Distinction is made between symmetric (Section III.B) and antisymmetric 203 (SectionIII.C) modes.

\section{B. Symmetric modes}

\section{Effect of propagation direction on ZGV existence and features}

Fig.2 presents the dispersion curves of a selection of symmetric Lamb modes $\left(\mathrm{S}_{1}, \mathrm{~S}_{11}, \mathrm{~S}_{26}\right.$ and $\mathrm{S}_{39}$ ) propagating in the $\mathrm{P}_{31}$ plane of an iodic acid plate, as an example. With increasing the order of the modes, the number of $\mathrm{ZGV}$ points, characterized by a minimum or a maximunin the phase velocity branch, increases: $S_{1}, S_{11}, S_{26}$ and $S_{39}$ modes have 1, 2, 3 and 4 ZGV points, 
211 respectively. The appearance of a mode with four ZGV points $S_{39}$ is the most interesting result 212 in $\mathrm{P}_{31}$, as illustrated in Fig. 2.

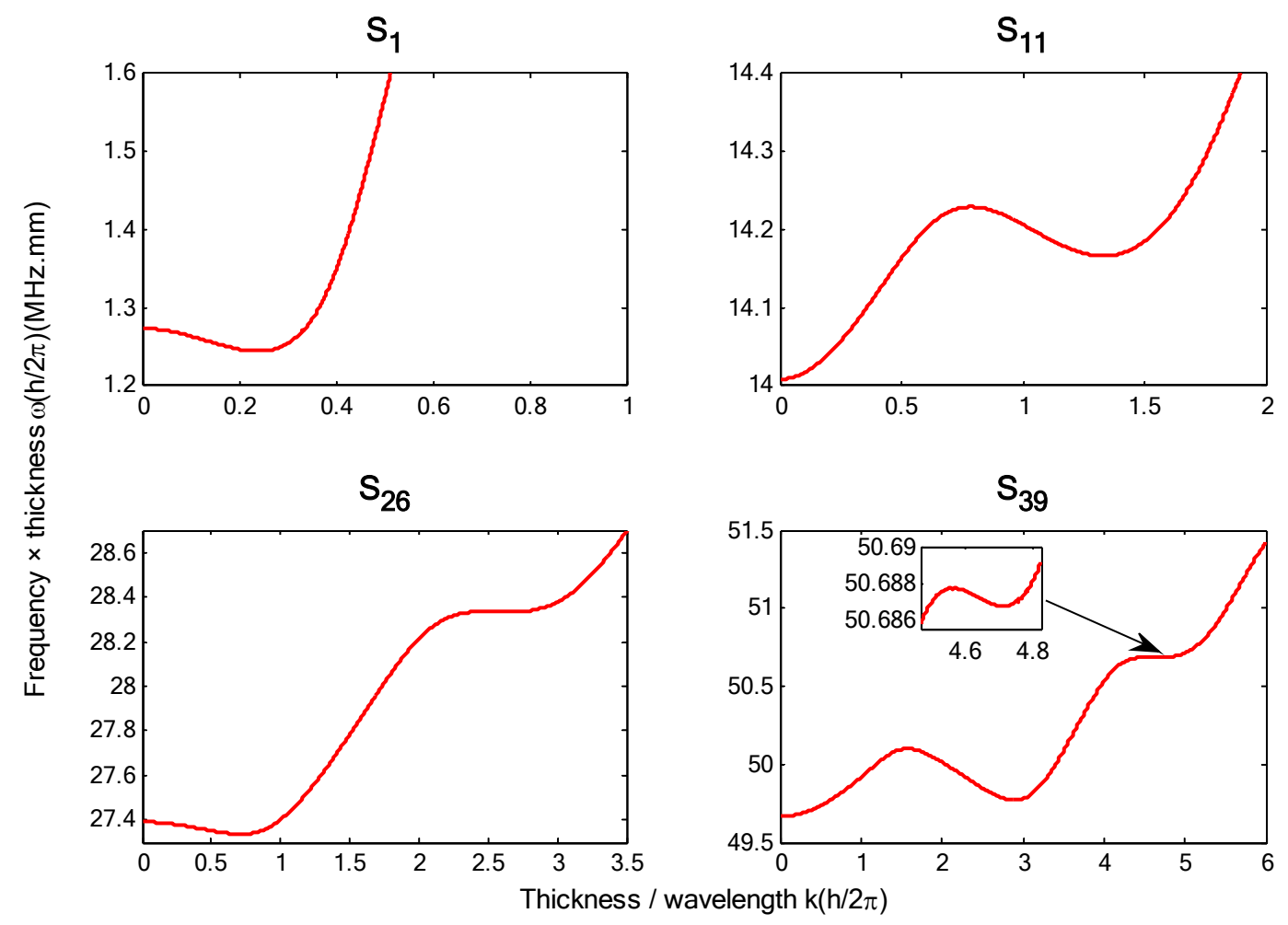

213

214 FIG.2. Dispersion curves of $\mathrm{S}_{1}, \mathrm{~S}_{11}, \mathrm{~S}_{26}$ and $\mathrm{S}_{39}$ modes travelling in the $\mathrm{P}_{31}$ plane of an iodic acid plate. 


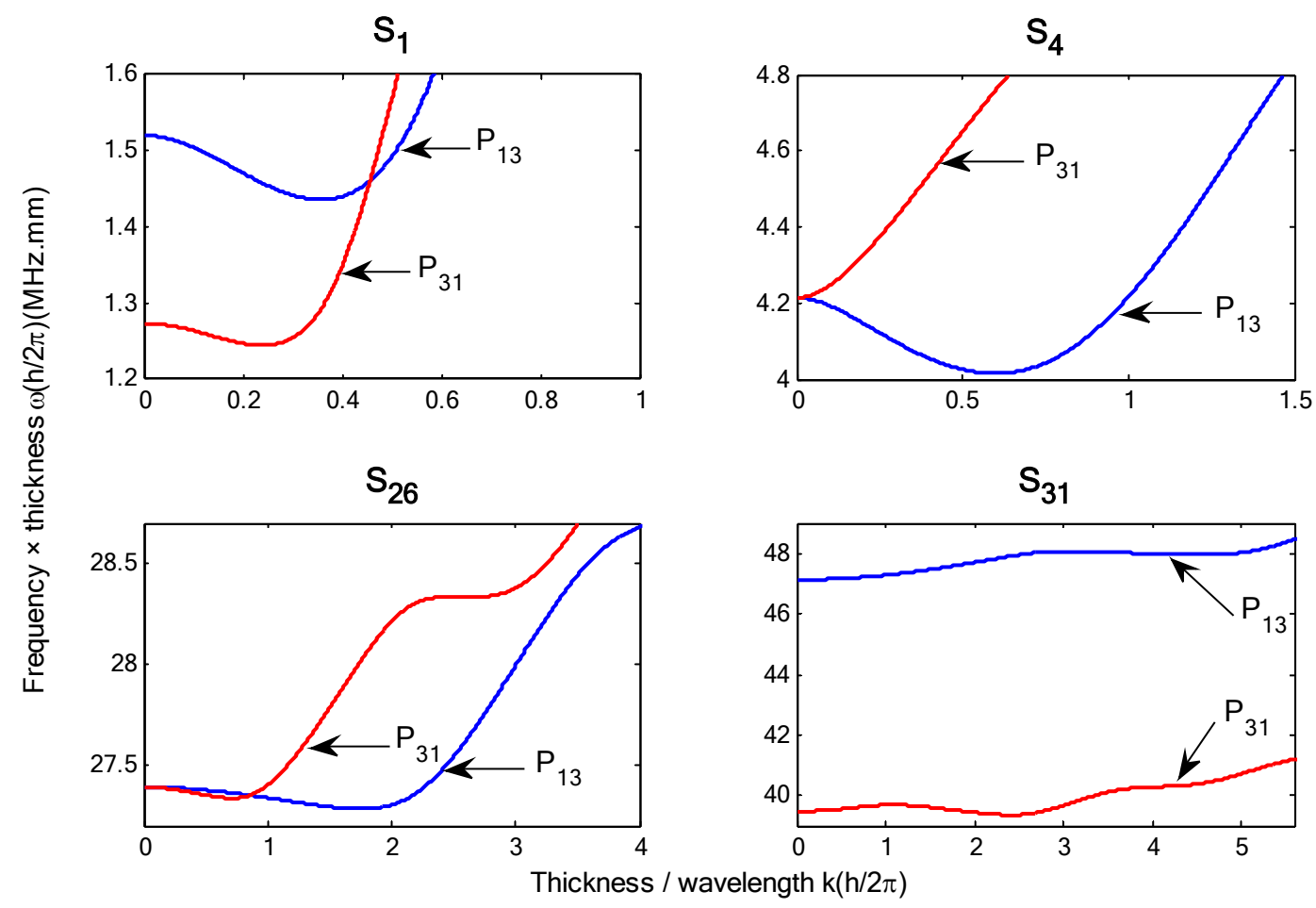

216

217 FIG.3. Graphs of $\mathrm{S}_{1}, \mathrm{~S}_{4}, \mathrm{~S}_{26}$ and $\mathrm{S}_{31}$ modes comparing plane $\mathrm{P}_{31}$ to plane $\mathrm{P}_{13}$.

218 Figure 3 shows the dispersion curves of the same modes, $S_{1}, S_{4}, S_{26}$ and $S_{31}$, travelling along 219 the $\mathrm{x}_{1}$ and $\mathrm{x}_{3}$ directions of the $\mathrm{P}_{13}$ and $\mathrm{P}_{31}$ planes in $\mathrm{HIO}_{3}$ plate. The ZGV points are very 220 sensitive to the anisotropy. For example, the $\mathrm{S}_{26}$ mode has one $\mathrm{ZGV}$ point in the $\mathrm{P}_{13}$ plane, which 221 becomes three ZGV points in the $\mathrm{P}_{31}$ plane (see Fig. 3). The same behavior was found in all 222 other modes.

223 Table 4 shows a list of the symmetric Lamb modes according to the number of ZGV points in 224 the $P_{13}$ and $P_{31}$ planes, respectively: this proves the strong dependencies of ZGV points on the 225 propagation direction. For example, the $\mathrm{S}_{44}$ mode has one $\mathrm{ZGV}$ point in the $\mathrm{P}_{13}$ plane, which 226 becomes three ZGV points in the $\mathrm{P}_{31}$ plane (see Table 4). The ZGV frequency is more sensitive 227 to the crystallographic plane in which the waves travel than to the cutoff frequency. While the cutoff frequency is only dependent on the change of propagation plane when $\mathrm{N}$, the number of nodes across the thickness of the plate, is odd, the ZGV frequencies are different in all cases. 
230 E.g. in case of the $\mathrm{S}_{4}$ mode, even the number of $\mathrm{ZGV}$ points changes when changing the plane 231 from $\mathrm{P}_{13}$ to $\mathrm{P}_{31}$.

\begin{tabular}{|c|c|c|c|c|c|}
\hline plane & $\begin{array}{l}\text { Modes with no } \\
\text { ZGV point }\end{array}$ & $\begin{array}{l}\text { Modes with one } \\
\text { ZGV point }\end{array}$ & $\begin{array}{l}\text { Modes with two } \\
\text { ZGV points }\end{array}$ & $\begin{array}{l}\text { Modes with } \\
\text { three ZGV } \\
\text { points }\end{array}$ & $\begin{array}{l}\text { Modes with } \\
\text { four ZGV } \\
\text { points }\end{array}$ \\
\hline $\mathbf{P}_{31}$ & $\begin{array}{l}S_{0}, S_{2}, S_{4}, S_{5} \\
S_{9}, S_{16}\end{array}$ & $\begin{array}{l}S_{1}, S_{3}, S_{6}, S_{7}, S_{8} \\
S_{10} S_{12}, S_{14}, S_{18}, \\
S_{20}, S_{22}, S_{24}, S_{30} \\
S_{32}\end{array}$ & $\begin{array}{l}S_{11}, S_{13}, S_{17}, S_{19}, \\
S_{21} S_{23}, S_{25}, S_{27}, \\
S_{33}, S_{30} S_{35}, S_{37}, \\
S_{40}\end{array}$ & $\begin{array}{l}S_{26}, S_{28}, S_{36} \\
S_{31}, S_{38}, S_{42} \\
S_{44}, S_{46}\end{array}$ & $\mathbf{S}_{39}$ \\
\hline $\mathbf{P}_{13}$ & $\begin{array}{l}S_{0}, S_{2}, S_{3}, S_{5}, S_{9} \\
S_{10}, S_{13}, S_{16}\end{array}$ & $\begin{array}{l}S_{1}, S_{4}, S_{6}, S_{7}, S_{8} \\
S_{12}, S_{14}, S_{18}, S_{20} \\
S_{22}, S_{24}, S_{26}, S_{32} \\
S_{34}, S_{44}\end{array}$ & $\begin{array}{l}S_{11}, S_{15}, S_{17}, S_{19}, \\
S_{21}, S_{23}, S_{25}, S_{27}, \\
S_{28}, S_{29} S_{30}, S_{31}, \\
S_{36}, S_{38}, S_{42}\end{array}$ & $S_{40}, S_{46}$ & \\
\hline
\end{tabular}

238 TABLE IV: Classification of symmetric Lamb modes according to the number of ZGV points 239 in the $P_{13}$ and $P_{31}$ plane, respectively.

241 Fig. 4 shows the occurrence of multiple ZGV points limited to Lamb waves propagating in the 
243 possesses a single $\mathrm{ZGV}$ point, regardless of the plane of propagation. However, as far as the 244 other modes are concerned, the number of their ZGV points differs from one plane to another.

245 This is due to the influence of the propagation direction on the ZGV phenomenon.

246 E.g. in case of the $S_{11}$ mode, even the number of $Z G V$ points changes when changing the plane.
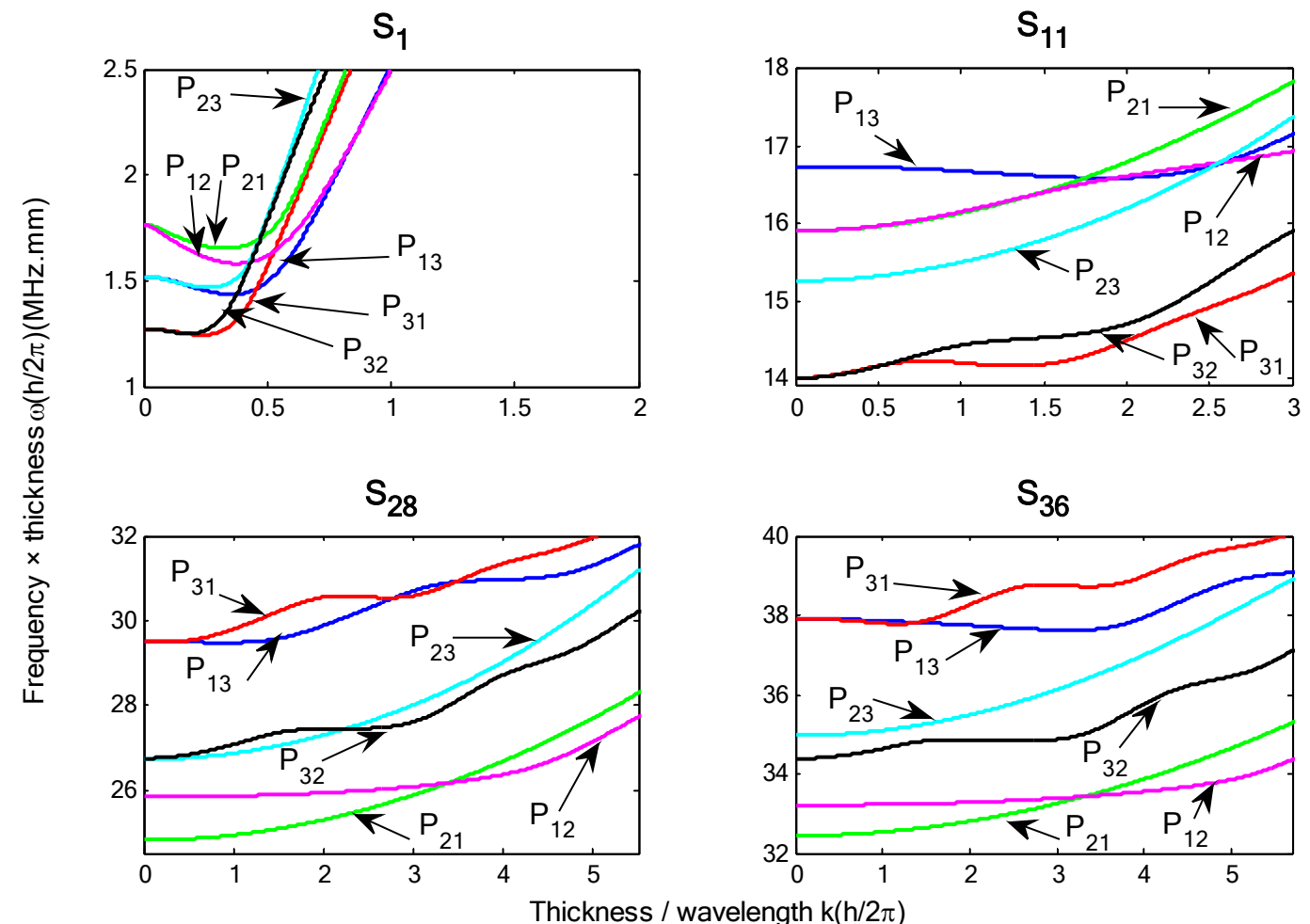

FIG.4. Dispersion curves of $\mathrm{S}_{1}, \mathrm{~S}_{11}, \mathrm{~S}_{28}$ and $\mathrm{S}_{36}$ symmetric Lamb waves running along an iodic acid plate in different crystallographic planes.

\section{Effect of elastic constants on ZGV frequencies}

Continuing earlier research on ZGV modes [7, 19, 51], in the following, we have investigated the dependence of the $\mathrm{ZGV}$ frequencies on the values of the different elastic constants $\left(\mathrm{c}_{11}, \mathrm{c}_{13}\right.$, $\mathrm{c}_{33}, \mathrm{c}_{55}$ ). Each constant was successively varied by $5 \%$ and $10 \%$ with respect to the values with respect to the values listed in Table 1 , and propagation in the $\mathrm{P}_{13}$ plane was considered. A general observation is that each ZGV frequency depends on specific constants. Fig.5, for 
258 instance, displays the dispersion of the $\mathrm{S}_{1}$ mode for different variations of the elastic constants.

259 The elastic constants that affect the $\mathrm{S}_{1}-\mathrm{ZGV}$ frequency mostly are $\mathrm{c}_{11}$ and $\mathrm{c}_{33}$. Variations in $\mathrm{c}_{13}$ 260 and $c_{55}$ hardly result in any effect.

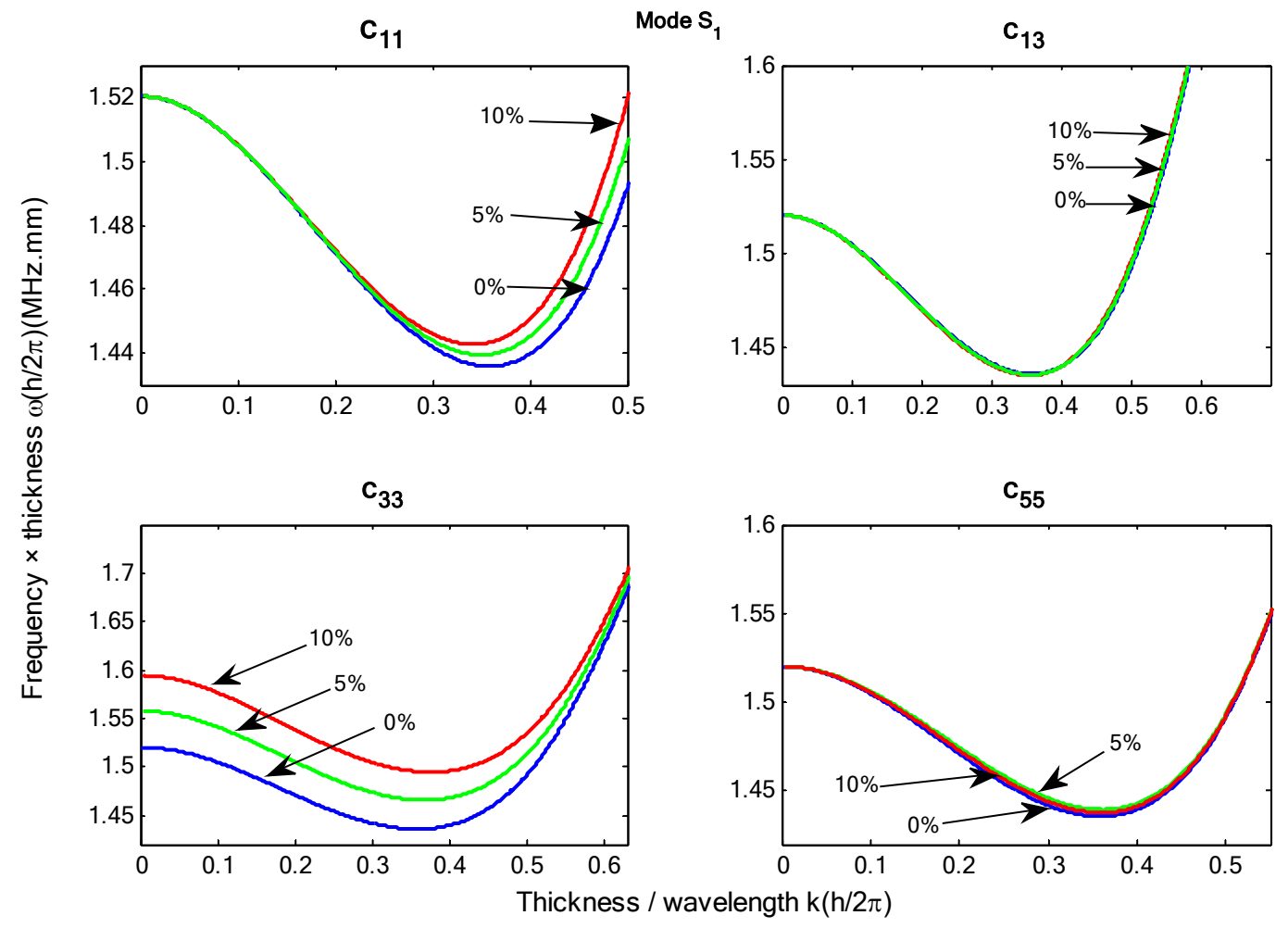

FIG.5. Effect of variations of the elastic constants $\mathrm{c}_{11}, \mathrm{c}_{13}, \mathrm{c}_{33}$, $\mathrm{c}_{55}$ on the $\mathrm{S}_{1}$ mode propagating in the $\mathrm{P}_{13}$ plane of an iodic acid - like plate( $0 \%$ original plate properties, $+5 \%$ and $+10 \%$ compared to the original values). Interestingly, in case of the $S_{7}$ mode (Fig.6), which possesses a single ZGV point in a genuine iodic acid plate, a change of $c_{33}$ and $c_{55}$ does not only considerably affect the ZGV frequency, 266 but, when large enough, it leads to the emergence of an additional ZGV point (for a 10\% 267 increase of $c_{33}$ ), or the disappearance of one (for a $5 \%$ or $10 \%$ increase of $c_{55}$ ). Variations in $\mathrm{c}_{11}$ and $\mathrm{c}_{13}$ only lead to a moderate change of ZGV frequency.

269 Also for the $\mathrm{S}_{30}$ mode (Fig.7), changes in $\mathrm{c}_{11}$ and $\mathrm{c}_{13}$ hardly result in any effect, while changes in $c_{33}$ and $c_{55}$ lead to the emergence or disappearance of ZGV points and to substantial changes of ZGV frequencies. 


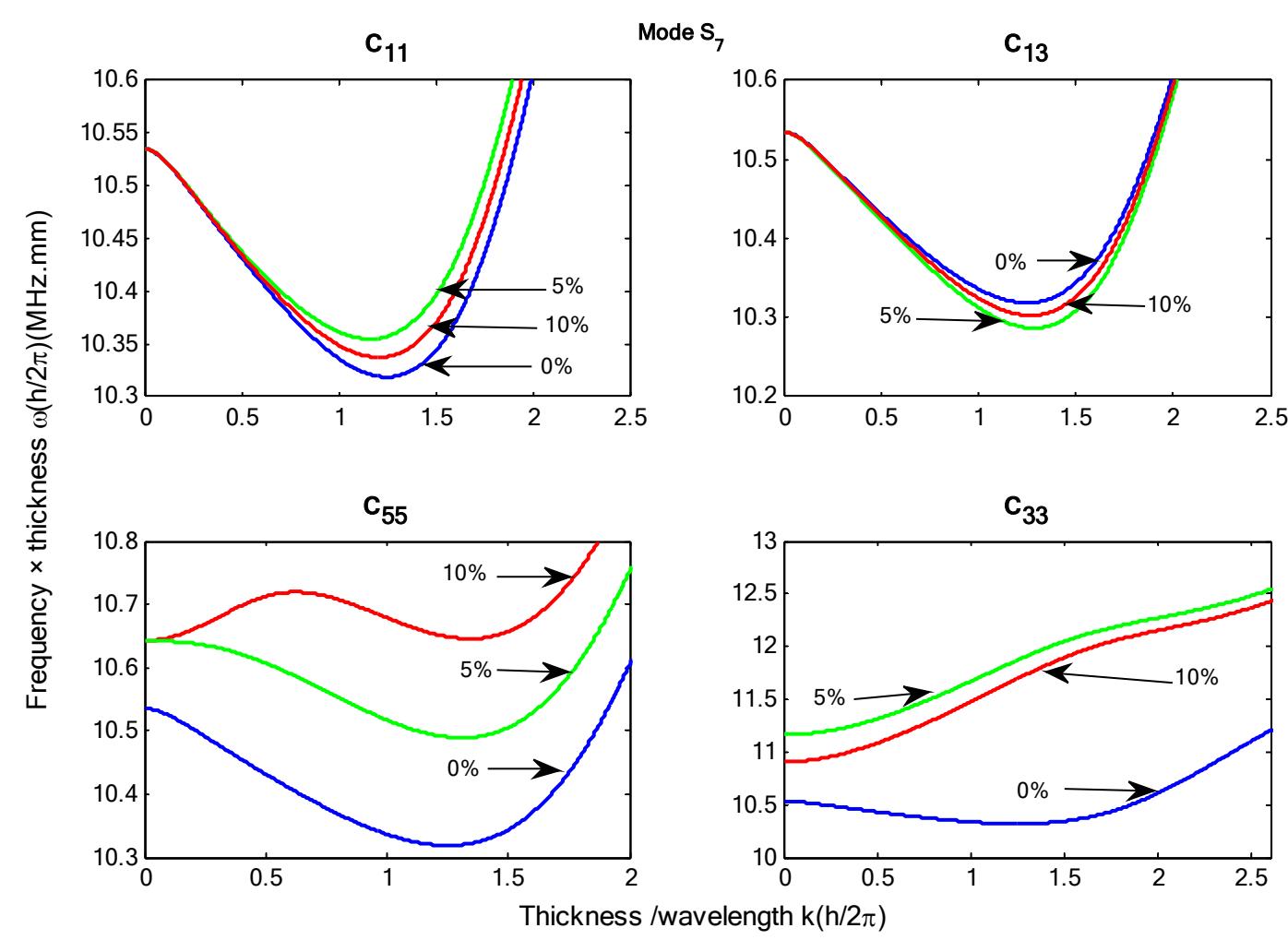

272

FIG.6. Effect of variations of the elastic constants $\mathrm{c}_{11}, \mathrm{c}_{13}, \mathrm{c}_{33}, \mathrm{c}_{55}$ on the $\mathrm{S}_{7}$ mode propagating in the $\mathrm{P}_{13}$ plane of an iodic acid plate $(0 \%$ : original plate properties, $+5 \%$ and $+10 \%$ compared to the original values).

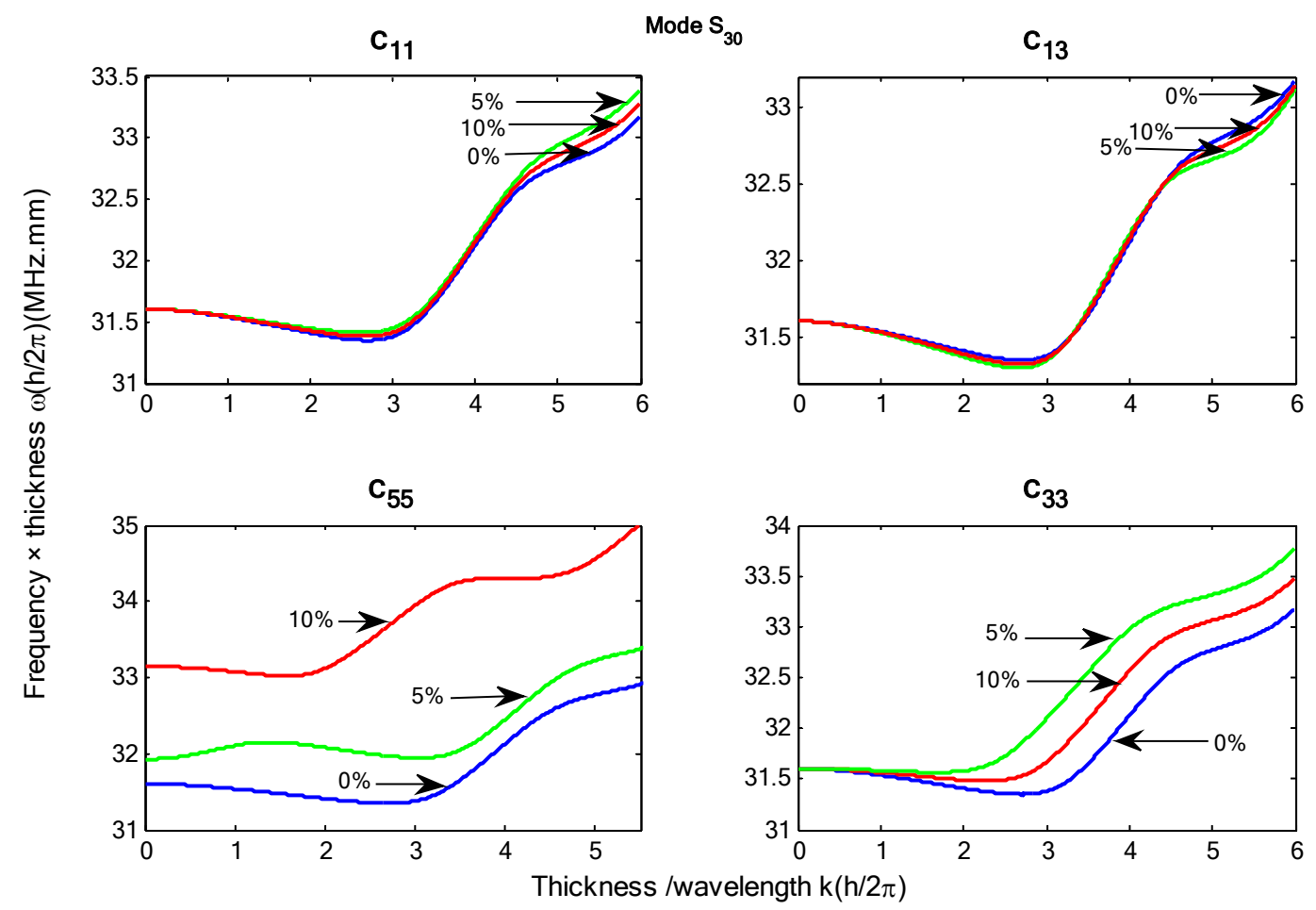


277 FIG.7. Effect of variations of the elastic constants $\mathrm{c}_{11}, \mathrm{c}_{13}, \mathrm{c}_{33}, \mathrm{c}_{55}$ on the $\mathrm{S}_{30}$ mode propagating in the $\mathrm{P}_{13}$ plane 278 of an iodic acid plate ( $0 \%$ : original plate properties, $+5 \%$ and $+10 \%$ compared to the original values) .

280 The observation that variations of $c_{33}$ and $c_{55}$ have a remarkably large effect on the existence 281 and features of the $S_{7}$ and $S_{30}$ mode can be understood from the fact that the concerned ZGV 282 frequencies are quite close to cutoff frequencies, which in turn are directly linked to $\mathrm{c}_{33}$ and $\mathrm{c}_{55}$ 283 via the velocities of longitudinal $\left(\mathrm{v}_{\mathrm{L}}=\left(\mathrm{c}_{33} / \rho\right)^{0.5}\right)$ and transverse $\left(\mathrm{v}_{\mathrm{T}}=\left(\mathrm{c}_{55} / \rho\right)^{0.5}\right)$ bulk waves, which 284 determine the standing wave conditions across the plate thickness. The very high sensitivity of 285 the $\mathrm{ZGV}$ features to $\mathrm{c}_{33}$ and $\mathrm{c}_{55}$ infer the efficiency of ZGV analysis for solving the inverse 286 problem, i.e. determining $\mathrm{c}_{33}$ and $\mathrm{c}_{55}$ by detecting $\mathrm{ZGV}$ modes.

\section{Antisymmetric case}

288 The analysis presented for symmetric Lamb waves in section III.B was also carried out for 289 antisymmetric waves. Similar tendencies were found. Figs.8 and 9, for instance, display a 290 pronounced difference in ZGV behavior between waves propagating in different crystallographic planes. 

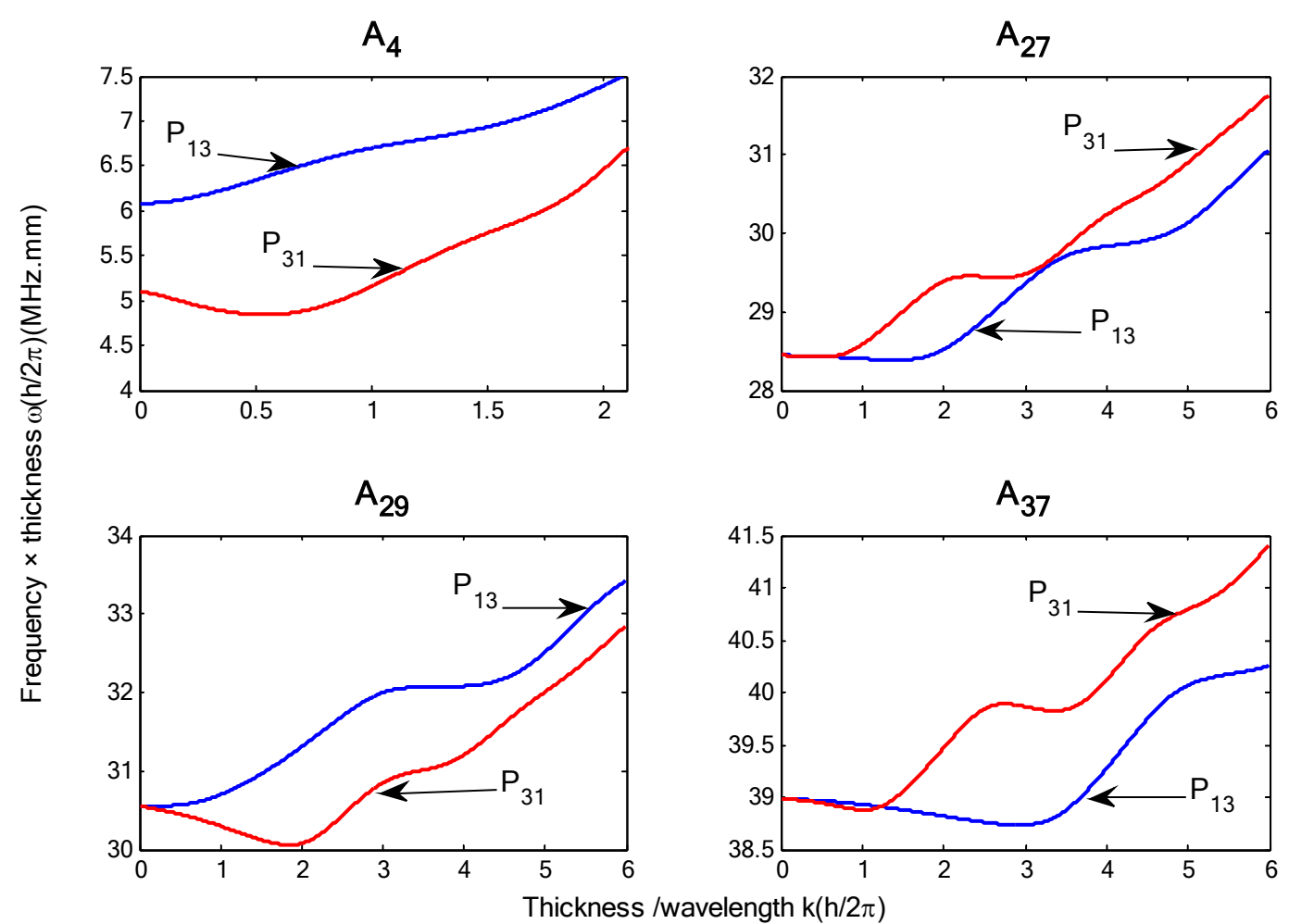

292

Thickness /wavelength $\mathrm{k}(\mathrm{h} / 2 \pi)$

293

294

295

296

297

298 single $\mathrm{ZGV}$ point in the $\mathrm{P}_{13}$ plane, compared to two in the $\mathrm{P}_{31}$ plane. planes.

FIG. 8. Dispersion curves of $A_{4}, A_{27}, A_{29}$ and $A_{37}$ Lamb waves propagating in the $P_{31}$ and $P_{13}$ crystallographic

Table V lists a classification of antisymmetric Lamb modes propagating in the $\mathrm{P}_{13}$ plane and in the $\mathrm{P}_{31}$ plane of an iodic acid plate, according to the number of ZGV points. Again the number of ZGV points depends on the crystallographic plane of propagation. E.g. the $\mathrm{A}_{16}$ mode has a 


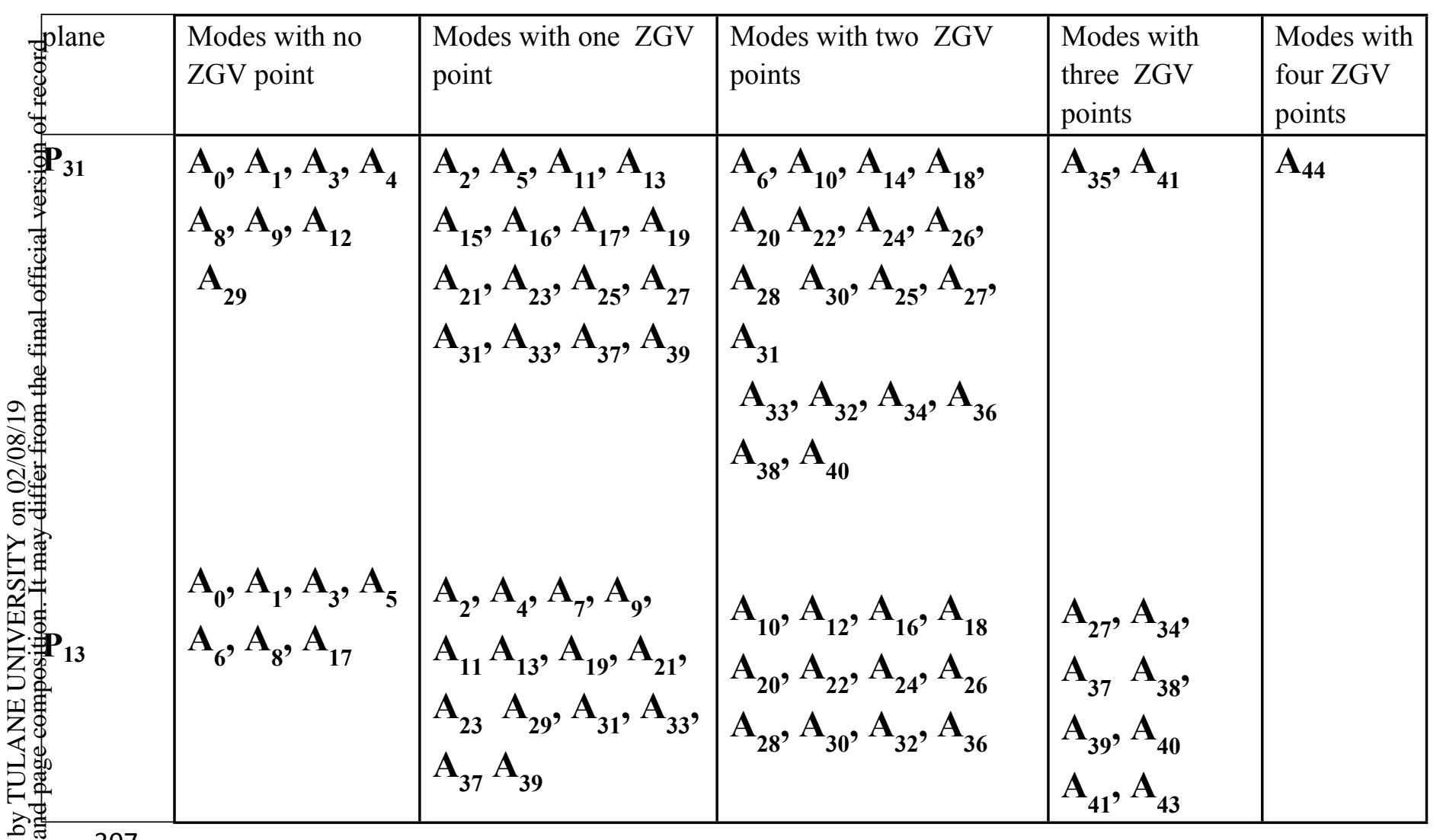

308 TABLE V: Classification of antisymmetric Lamb modes according to the number of ZGV 309 points in the $P_{13}$ and $P_{31}$ plane, respectively.

310 Further on, the following observations can be made: (i) Changing the plane in which the waves 311 are propagating affects cutoff frequencies if $\mathrm{N}$, the number of the nodes across the plate 312 thickness of the standing wave associated with those frequencies is even. In case $\mathrm{N}$ is odd, the 313 corresponding cutoff frequency remains unaffected. This correlation is opposite in the case of 314 symmetric Lamb waves. (ii) The modes that exhibit ZGV points exhibit either 2 or 4 of them 315 when $\mathrm{N}$ is even and 1 or 3 when $\mathrm{N}$ is odd. Lamb modes with $4 \mathrm{ZGV}$ points occur both in the 316 symmetric and antisymmetric case. (iii) The lowest antisymmetric mode for which multiple $317 \mathrm{ZGV}$ points are present is $\mathrm{A}_{6}$. In the case of symmetric mode, the lowest order mode with more 318 than one $Z G V$ point is $S_{11}$. (iv) The influence of changing elastic constants on the ZGV features 319 is similar to the symmetric case: $\mathrm{C}_{33}$ and $\mathrm{C}_{55}$ have an effect on the number of ZGV points, while 320 $\mathrm{C}_{11}$ and $\mathrm{C}_{13}$ only influence the $\mathrm{ZGV}$ frequency (see Figs.10 and 11). 
$\mathrm{A}_{2}$

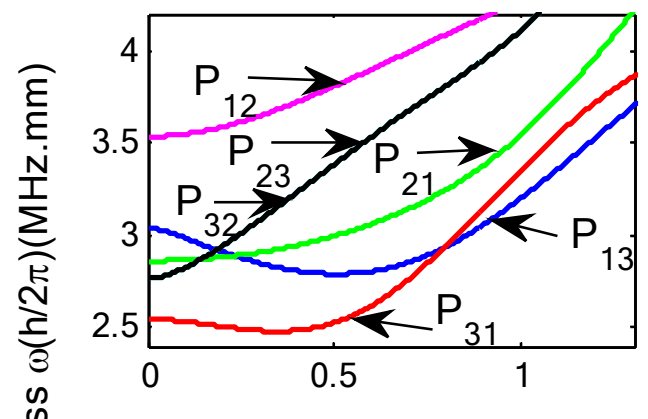

$A_{27}$

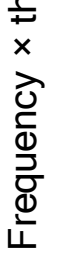

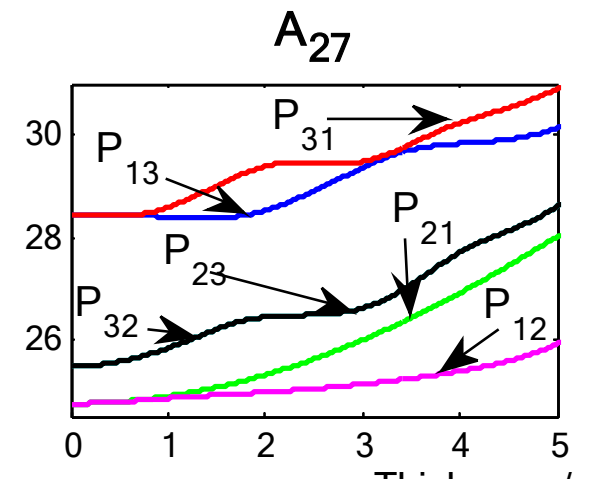

$A_{6}$

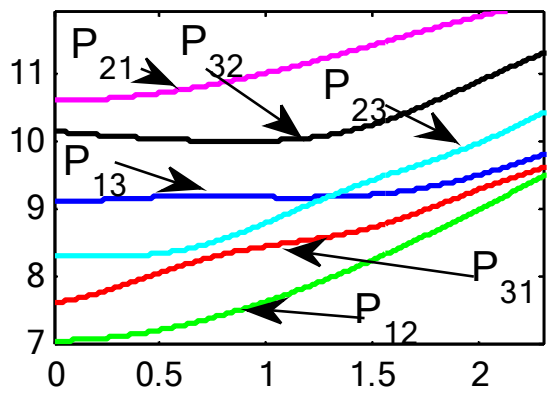

$A_{37}$

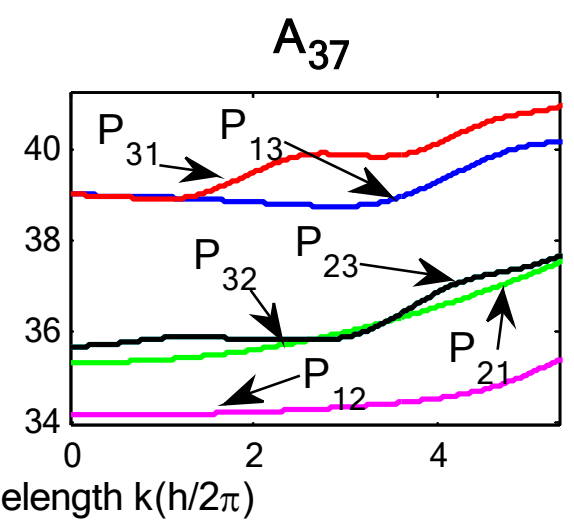

321

322

FIG. 9.Dispersion curves of $A_{2}, A_{6}, A_{27}$ and $A_{37}$ antisymmetric Lamb modes running along an iodic acid plate 323 in different crystallographic planes. 


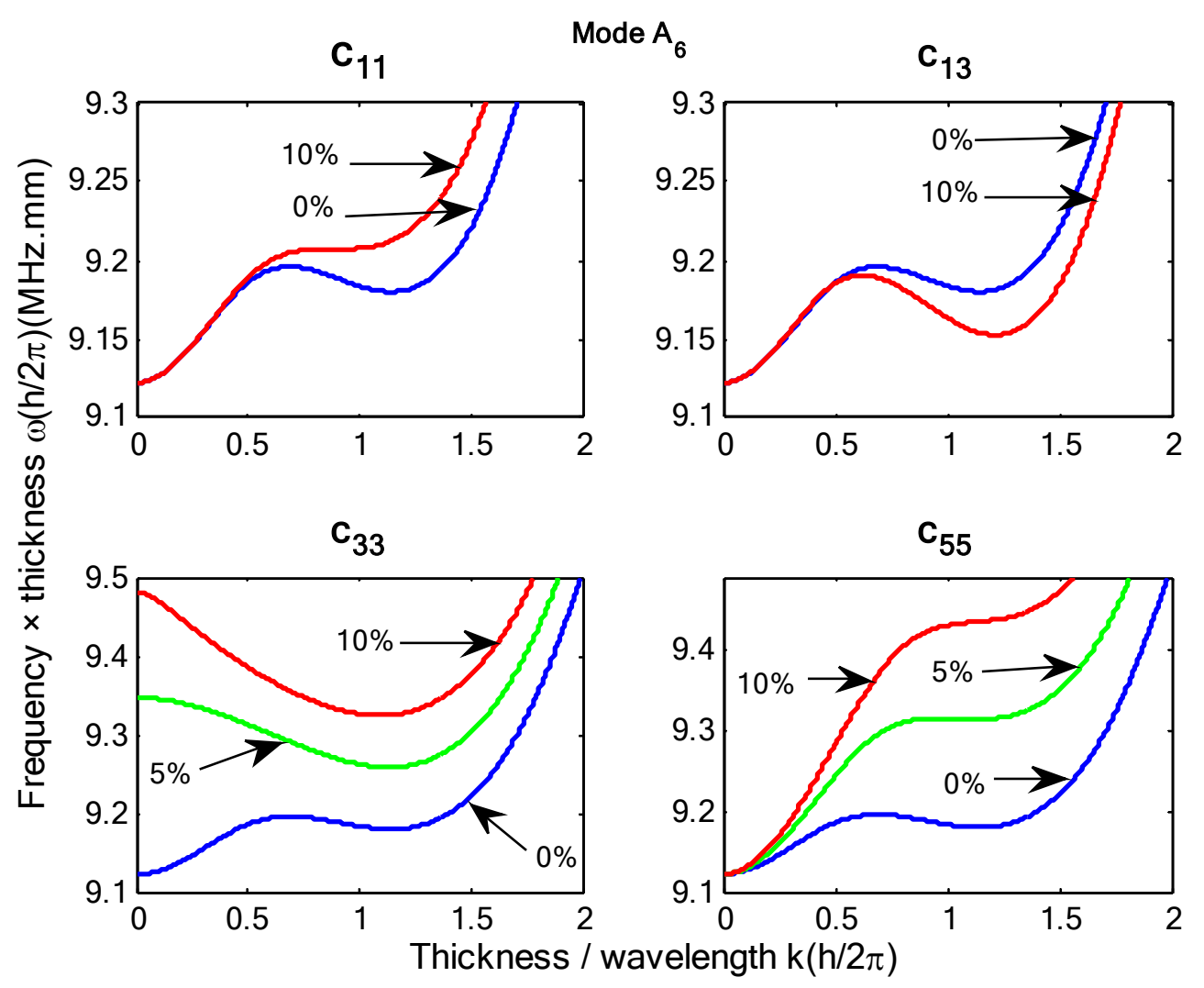

325

326

FIG.10. Effect of variations of the elastic constants $\mathrm{c}_{11}, \mathrm{c}_{13}, \mathrm{c}_{33}, \mathrm{c}_{55}$ on the $\mathrm{A}_{6}$ mode propagating in the $\mathrm{P}_{13}$ plane 


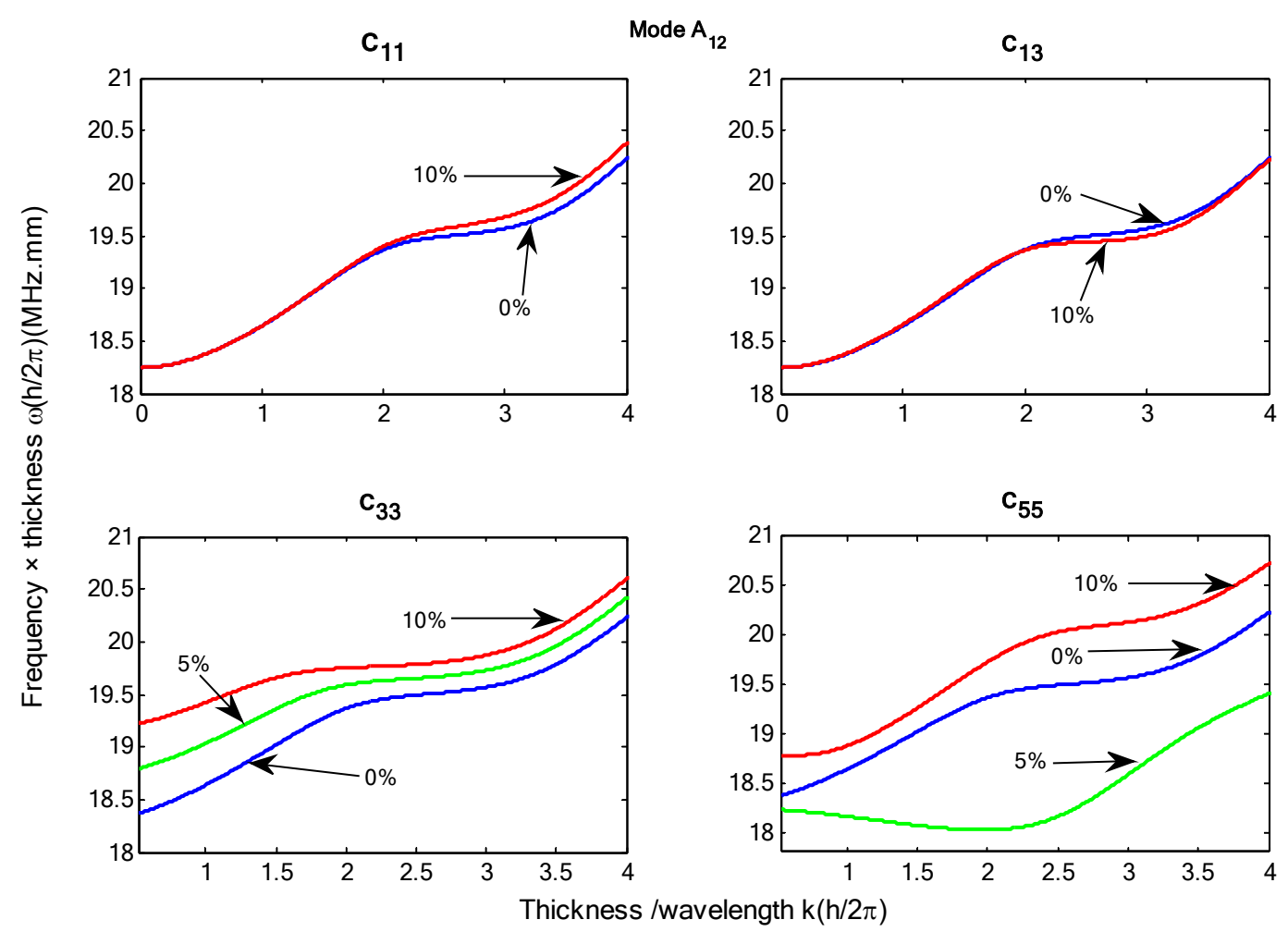

330

331

332

333

334

335

336

337

338

339

340

341

342

FIG.11. Effect of variations of the elastic constants $c_{11}, c_{13}, c_{33}, c_{55}$ on the $A_{12}$ mode propagating in the $P_{13}$ plane of an iodic acid plate ( $0 \%$ : original plate properties, $+5 \%$ and $+10 \%$ compared to the original values).

\section{CONCLUSION}

The paper studies the propagation of symmetric and anti-symmetric Lamb waves along two mutually orthogonal propagation directions in three crystallographic planes. A detailed analysis is presented of dispersion curves in the $\mathrm{P}_{13}$ plane. Several zero group velocity (ZGV) points were found and the dependence of their frequencies on each elastic constant $\left(\mathrm{c}_{11}, \mathrm{c}_{13}, \mathrm{c}_{33}\right.$, $c_{55}$ ) of the $\mathrm{HIO}_{3}$ plate material was investigated. It was found that $\mathrm{c}_{33}$ and $\mathrm{c}_{55}$ affect the number of the ZGV points, while $c_{11}$ and $c_{13}$ affect the frequency of the $\mathrm{ZGV}$ point. The study has demonstrated that the $\mathrm{ZGV}$ points are strictly related to the material plate constants and to its crystallographic properties: this suggests that the experimental assessment of ZGVs should give 
343

344

345

346

347

348

349

350

351

352

353

354

355

356

357

358

359

360

361

362

363

364

365

366

an adequate approach to extract some of the elastic property of plates, and to detect in a very sensitive way defects that affect the plate elasticity.

\section{ACKNOWLEDGMENTS}

The authors are grateful for the funding provided to LPM laboratory by the Tunisian Ministry of Higher Education and Scientific Research. They also extend their thanks to Mrs. Leila Mahfoudhi and Mr. Wassim Hariz, English Language Teachers at the Faculty of Science of Sfax, for proofreading and polishing the language of the manuscript.

\section{REFERENCES}

[1] Lynnworth, C. Lawrence. Academic press, (2013).

[2] W. J. Staszewski, B. C. Lee, R. Traynor. Meas. Sci. Technol. 18(3), 727, (2007).

[3] L. Martinez, N. Wilkie-Chancellier, C. Glorieux, B. Sarens, E. Caplain. J. Phys. Conf. Ser. 195, 012009, (2009).

[4] L. Martinez, N. Wilkie-Chancellier, C. Glorieux. J. Acoust. Soc. Am. 123(5), 38463846, (2008).

[5] W. Gao, C. Glorieux. AJT. Int. J. Eng. Sci. 41, 219, (2003).

[6] M. Cès, D. Royer, C. Prada. J. Acoust. Soc. Am. 132(1), 180, (2012).

[7] B. Verstraeten, X. Xu, L. Martinez, C. Glorieux. AIP Conference Proceedings. 1433, 423-6, (2012).

[8] W. Gao, C. Glorieux, K. Van De Rostyne, M. Wevers, W. Lauriks, J. Thoen. AIP Conf. Proc. 454, 1, (1999).

[9] L. Yuan, Z. Shen, X. Ni, J. Lu. J. Appl. Phys. 106(2), 023529, (2009).

[10] T. Hussain, F. Ahmad. J. Acoust. Soc. Am. 132(2), 641, (2012).

[11] O. Balogun, T. W. Murray, C. Prada. J. Appl. Phys. 102(6), 1, (2007). 
367

368

369

370

371

372

373

374

375

376

377

378

379

380

381

382

383

384

385

386

387

388

389

390

391

[12] C. Prada, O. Balogun, T. W. Murray. Appl. Phys. Lett. 87(19), 1, (2005).

[13] M. Cès, D. Clorennec, D. Royer, C. Prada. Rev. Sci. Instrum. 82(11), 114902, (2011).

[14] M. Cès, D. Clorennec, D. Royer, C. Prada. J. Acoust. Soc. Am. 130(2), 689, (2011).

[15] C. Prada, D. Clorennec, D. Royer. J. Acoust. Soc. Am. 124(1), 203, (2008).

[16] D. Clorennec, C. Prada, D. Royer. IEEE Trans. Ultrason. Ferroelectr. Freq. Control. 57(5), 1125, (2010).

[17] S. D. Holland, D. E. Chimenti. Ultrasonics. 42(1-9), 957, (2004).

[18] A. Gibson, J. S. Popovics. J. Eng. Mech. 131(4), 438, (2005).

[19] C. Prada, D. Clorennec, T. W. Murray, D. Royer. J. Acoust. Soc. Am. 126(2),620, (2009).

[20] C. Grünsteidl, T. W. Murray, T. Berer, I. A. Veres. Ultrasonics. 65(10), 1, (2016).

[21] M. S. Bouhdima, M. Zagrouba, M. H. Ben Ghozlen. Can. J. Phys. 90(2), 159, (2012).

[22] C. Prada, D. Clorennec, D. Royer. J. Appl. Phys. 101(3), 1, (2007).

[23] O. Tofeldt, N. Ryden. J. Acoust. Soc. Am. 141(5), 3302, (2017).

[24] C. Prada, D. Clorennec, D. Royer, T. W. Murray. Appl. Phys. Lett. 89(2), 3, (2006).

[25] V. Tournat, S. Raetz, N. Chigarev, C. Mechri, J. Blondeau, B. Campagne, V. E. Gusev, V. Tournat. NDT E Int. 85, 13, (2017).

[26] I. Tolstoy, E. Usdin. J. Acoust. Soc. Am. 29(1), 37, (1957).

[27] K. Negishi. 1978. J. Acoust. Soc. Am. 64(6), S63, (1978).

[28] C. Prada, D. Clorennec, D. Royer. Wave Motion. 45(6), 723, (2008).

[29] M. Zagrouba, M. S. Bouhdima. Can. J. Phys. 94(11), 1189, (2016).

[30] M. Zagrouba, M. S. Bouhdima, M. H. Ben Ghozlen. Adv. Acoust. Vib. 2014, 1, (2014).

[31] F. M. Werby, H. Uberall. J. Acoust. Soc. Am. 111(6), 2686, (2002).

[32] A. H. Meitzler. J. Acoust. Soc. Am. 38(5), 835, (1965).

[33] E. Kausel. J. Acoust. Soc. Am. 131(5), 3601, (2012). 


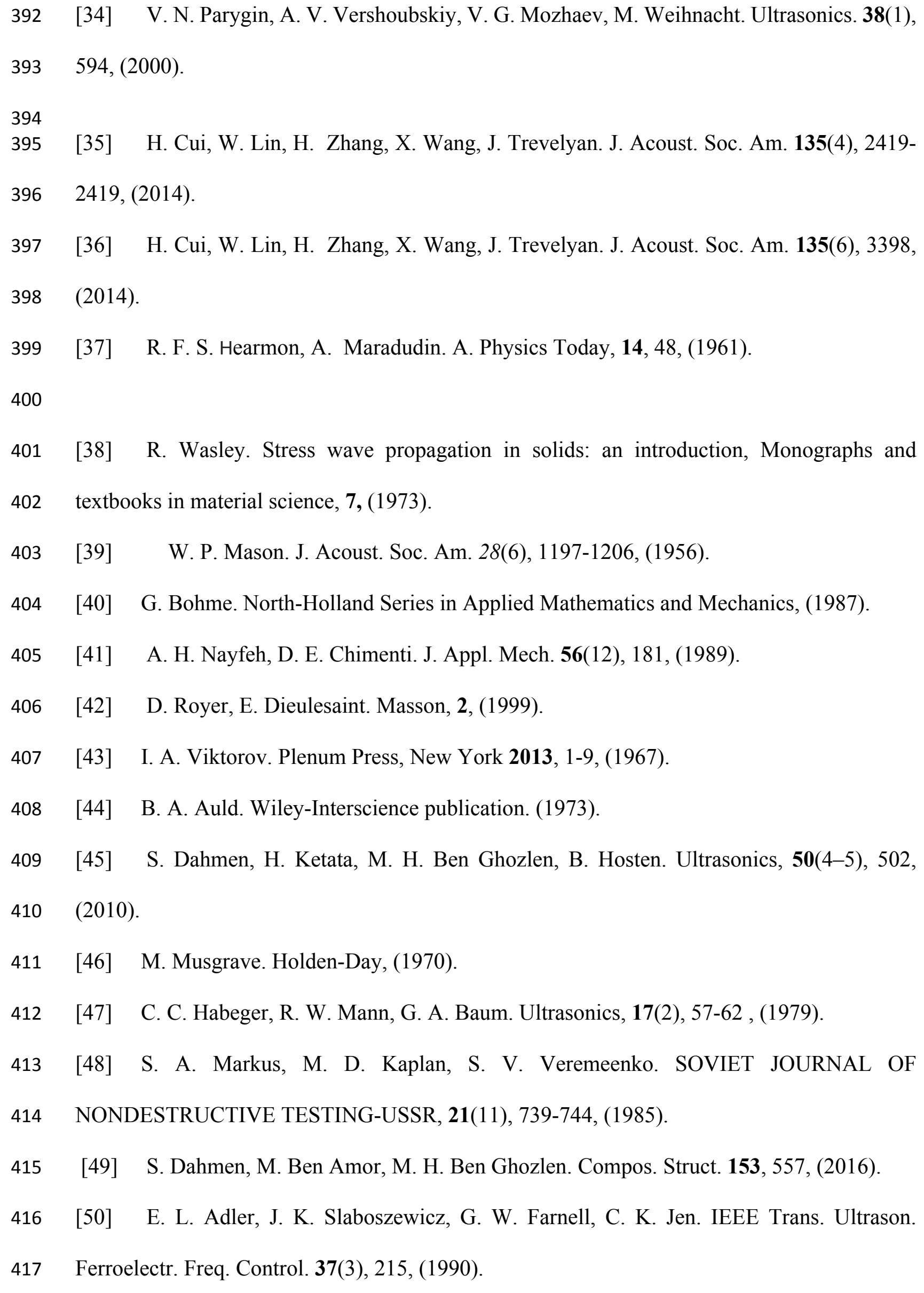


418 [51] J. Laurent, D. Royer, T. Hussain, F. Ahmad, C. Prada. J. Acoust. Soc. Am. 137(6), $4193325,(2015)$.

420 